\title{
Correspondence
}

\section{Mental Health Guardianship}

DeAR SIRS

My colleagues and I, working with the mentally handicapped here in the Grampian region, found much of interest in the paper by $\mathrm{Dr}$ Hughes entitled 'Mental Health Guardianship - a Change for the Better?' (Bulletin, October 1982, 6, 176-77). Scottish Mental Health legislation (including that relating to Guardianship) is also in the process of being amended and a consultation paper has recently invited comments.

This paper suggested that powers of Guardianship be limited and that the emphasis be placed on their protective rather than their restrictive functions. It commented too on the continuing place there seemed to be for Guardianship despite the fall in numbers in Scotland.

Here in the Grampian region, quite against the national trend, there has recently been a modest increase in the numbers of mentally handicapped individuals who are subject to Guardianship. It is being used as an alternative both to probation and to prolonged leave of absence from hospital. It also fulfils a useful role in supervising those who are mentally handicapped and who live with people to whom they are unrelated-the Mental Welfare Commission for Scotland point out the desirability of formal Guardianship in such settings in their publication No Folks of Their Own.

We would agree with Dr Hughes that local authorities do seem uncertain about their Guardianship powers, but not only are they reluctant to take on such responsibilities, they seem seldom to think of Guardianship as being relevant in the eighties. Here in Grampian, however, we feel certain there is a continuing place for Guardianship as a means of ensuring an appropriate quality of care for a number of mentally handicapped persons living in the community.

Woodlands Hospital

ROBERT D. DRUMMOND

Aberdeen

\section{Anti-Semitism in Vienna}

\section{Dear Sirs}

The 7th World Congress of Psychiatry is scheduled to take place in Vienna in July 1983. The Austrian Chancellor, Dr Bruno Kreisky, heads the Honorary Presidium.

There have been several anti-Semitic outrages in Vienna recently, including attacks on the home of Simon Wiesenthal, the famed Nazi hunter and survivor of Auschwitz, and on a synagogue. Following the latter episode, not only did Dr Kreisky not attend the memorial service for the victims, but he released a statement charging that the incident was partially a result of Israel's policies in the Middle East. Dr Kreisky's behaviour is all the more deplorable in view of his Jewish origin and the fact that several members of his family died in Nazi concentration camps during World War II.

I think there is something grotesque in holding an important international mental health conference in the country which expelled Sigmund Freud in 1938, and whose Chief Executive today thinks it appropriate to rationalize the murder of Jews in his nation's capital by blaming Israel and its policies. I, for one, will not attend the Congress, and hope that many of my colleagues in the Royal College of Psychiatrists will feel the same.

Fred B. Charatan

106 Barry Lane

Syosset, New York 11791

\section{Planning registrar and senior registrar training in mental handicap}

\section{DeAR SIRS}

Dr Armah-Kwantreng's letter (Bulletin, September 1982, 6,163 ) cannot go unanswered in case it be construed as relating to Botleys Park Hospital, as, by implication, it suggests a dire situation regarding teaching in this hospital.

Nothing could be farther from the truth. In the year to June 1982 there was a record number of admissions, presenting a great variety of clinical material. Weekly case conferences are held by all the consultants on in-patients, and junior staff attend these. There are weekly out-patient clinics which the juniors are expected to attend. There are valuable sessions available in child psychiatry: the senior registrar posts are joint appointments with child psychiatry. There is a new DGH psychiatric unit in the campus, at whose teaching sessions our juniors are most welcome. This is not to mention the DGH itself where general medical and surgical training is conducted at both undergraduate and postgraduate levels. In fact, the campus may be unique, countrywide, in terms of such a concatenation of a large Mental Handicap Hospital, a DGH and an acute Psychiatric Unit.

We, in Botleys Park Hospital, have weekly seminars throughout the year, which many outside professionals attend. There is an excellent library which is kept up to date in terms of acquisitions, despite the serious lack of a librarian, and an extensive photocopy library devoted to psychiatry and mental handicap, which includes most of the recommended reading list from the College. We have probably the largest set of teaching slides in the Region. A major research paper has come out of this hospital this year, 